\title{
How Old is Old? Employing Elderly Teachers in the Private Sector Schools in Sri Lanka
}

\author{
L A P Madhuwanthi ${ }^{1}$ \\ ${ }^{1}$ Graduate School of Public Administration, National Institute of Development Administration (NIDA), Bangkok, \\ Thailand \\ Correspondence: L A P Madhuwanthi, Graduate School of Public Administration, National Institute of Development \\ Administration (NIDA), Bangkok, Thailand. E-mail: pavithram1@gmail.com
}

Received: August 21, 2016

Accepted: September 9, 2016

Online Published: September 10, 2016

doi:10.5430/ijhe.v5n4p27

URL: http://dx.doi.org/10.5430/ijhe.v5n4p27

\begin{abstract}
The purpose of this paper is to explore why private sector schools in Sri Lanka employ elderly teachers (ETs). This paper used semi-structured in-depth interviews with 9 employers/principals in the private sector schools in Sri Lanka. The study found that the reasons for employing ETs in the private sector schools were shortfall of English medium qualified teachers, lack of teachers with adequate pedagogical knowledge, high job attrition among the young teachers, competence of ETs, and special expertise contribution of ETs as administrators, mentors and the guardians of school culture. Further, financial constraints and reputational issues faced by particularly the new and small private sector schools caused to employ ETs. This paper indicated that employment opportunities available for ETs in the private sector schools and the implications for the school education in Sri Lanka.
\end{abstract}

Keywords: Elderly teachers, Employment, Private sector schools

\section{Introduction}

The ageing arena, intertwined with the labour shortage calls attention for novel strategies to determine the size, structure, policies and practices in the labour market aiming at future economic growth of the country. At present the school education sector in Sri Lanka is one of the most important areas that is suffering from a dearth of qualified teachers in both the government and private sector schools. Though the number of schools and student enrolment is rising, studies have revealed that one of the main barriers to delivering a quality education to the children is the shortage of teachers among the schools in Sri Lanka (Balasooriya, 2013:143; Human Development Report Sri Lanka, 2012:69; Wettewa, n.d.; Hettige, 2005; Siyambalapitiya, 2005). According to the 2013 statistics from the Ministry of Education revealed that the gross student-teacher ratio of the government schools was 18 students per teacher while the private schools was 21 , indicating that comparatively teacher scarcity is higher among the private sector schools. The issue of the teacher shortage in Sri Lanka is multifaceted. The inadequacy of the number of teachers in the schools is one facet. Another aspect is the mismatch between the demand for and supply of teachers, which means the absence of specialized teachers for the subjects which have higher demand and relevancy for the contemporary job market, such as English, Science, Mathematics and Information Technology (Balasooriya 2012:144; Little \& Hettige, 2013; Wettewa, n.d.). The recent initiative of introducing the English medium of instruction (parallel to the vernacular medium of instruction) among the selected government and private schools in the country would demand a higher number of teaches that can instruct in the English medium. The establishment of international schools has aggravated the demand for English medium teachers that can teach national and British curricular in English medium. After almost 50 years of the adoption of vernacular languages in the school education system and to a certain extent in the universities in Sri Lanka, it is difficult to find teachers that are capable of imparting subject knowledge effectively to the students in English, as they have limited knowledge in English language (Little \& Hettige, 2013:236). All of that evidence indicates the necessity of maintaining an adequate and qualified teaching staff so as to address the educational needs and the labour market requirements of the country.

Those numerous challenging circumstances emerged in the school education system in Sri Lanka compelled the schools to welcome ETs back to the teaching cadre. In this study, the definition of "an elderly teacher is one that has retired from the government school after reaching the stipulated retirement age and is employed in a private sector school in Sri Lanka." The government regulation stated that the compulsory retirement age for a government school teacher is 60 , but alternatively teachers can retire between the age of 55-60 at their discretion. Consequently, the 
government schools do not permit to re-employ ETs after the retirement. Nevertheless, there is a tendency of employing ETs among the private sector schools in Sri Lanka. The researcher conducted a survey in 2015 among the 64 private sector schools in Sri Lanka as a part of this study in order to affirm whether the schools employed ETs. The results of the survey revealed that 54 out of 64 ( 84 percent) private sector schools employed ETs by 2015 (Table 1). The total number of ETs employed in those schools was 979, out of that many ETs were employed in the international schools.

Table 1. Employed Elderly Teachers in the Private Sector Schools in Sri Lanka

\begin{tabular}{lccc}
\hline Type of school & UPSs $^{\mathbf{1}}$ & ISs $^{\mathbf{2}}$ & Total \\
\hline No. of schools surveyed & 31 & 33 & 64 \\
No. of schools employed ETs & 25 & 29 & 54 \\
\% of schools employed ETs & $81 \%$ & $88 \%$ & $84 \%$ \\
& & & 979 \\
No. of ETs (in 2015) & 218 & 761 & \multicolumn{2}{c}{} \\
\hline urce: Survey data (2015) & 1 Unaided Private Schools & 2 International schools
\end{tabular}

Source: Survey data (2015)

Attracting ETs back to the schools is a novel trend that has been practicing in the Sri Lankan education labour market. However, obtaining the service of ETs by the schools has confirmed that even after the retirement ETs are still demanded by the employers especially during the ageing arena. Therefore the study is purporting to examine why do private sector schools in Sri Lanka employ elderly teachers?

The private sector schools in Sri Lanka are consisted of government aided private schools, government unaided private schools and international schools. The government aided schools are registered under the Ministry of Education in Sri Lanka and the government makes the payment of salaries of teachers, which is the largest operating cost of the schools. Therefore those schools charge a nominal fee from the students and they are practically considered as non-fee levying schools. The majority of the schools is under the Catholic denomination and is governed by a board of management. However, the Ministry of Education conducts thorough supervision of those schools and thereby administrative autonomy is limited in those schools. The unaided private schools (UPSs) do not receive any funding from the government and thus, the schools charge students a fee for admission and the education provided. Those schools are also governed by a board of management. Since they are registered under the Ministry of Education, they are subject to the government supervision. However, the board of management of the school has a great deal of autonomy in decision making and administration compared with the aided private schools. The concept of the international schools (ISs) in Sri Lanka began with the launching of liberal economic policies in 1977. The Board of Investment Act, enacted in 1978 would permit to register and open up ISs as foreign business entities. Later on the local business community got the opportunity to register and set up ISs under the Companies Act of 2007 as registered private limited liability companies. Since the ISs are not registered under the Ministry of Education, no direction or monitoring could be provided by the ministry. Thereby the board of management of the IS has a wider autonomy compared with the unaided and aided private schools.

Nonetheless, the current study of employing ETs in the private sector schools only concentrates on UPSs and ISs in Sri Lanka. That is because those two types of schools relatively experience higher levels of administrative autonomy in decision making and allowing much room for employing ETs according to the teacher requirement of the schools.

\section{Employment of Elderly Teachers}

The countries that face shortfall of teachers have adopted several alternatives such as hiring retired teachers, untrained/uncertified teachers, contract teachers, volunteer and community teachers, teaching candidates from other countries, providing on-the-job training and career-change programs designed to entice professionals into midcareer switches to teaching, and alternative certification programs to allow college graduates to postpone formal education training and begin teaching immediately (Ingersoll \& Smith, 2003; Fyfe, 2007; Bayer, Brinkkjaer, Plauborg, \& Rolls, 2009; Martinez, Frick, Kim, \& Fried, 2010). Recruiting teachers without full teacher qualifications may address the short-term teacher shortage problem; however, reducing the qualification requirements for entering the profession can further undermine teacher professionalism, as it can be seen as giving credence to a belief that "anyone can teach" (Bayer et al., 2009). This is an explicit indication that among the options available to the schools, absorbing experienced retired teachers into the system would comparatively be a more appropriate solution without deteriorating the quality of the teaching workforce. Therefore the employment of elderly/retired teachers is a vital 
measurement that has been exemplified by the schools that are facing the scarcity of teachers in many other countries (Bal \& Visser, 2011; Martinez et al., 2010; Botwinik \& Press, 2006; Redman \& Snape, 2002).

In Sri Lankan context also lack of qualified English medium teachers compels the private sector schools, especially ISs, to employ teachers purely based on their English language skills, yet those teachers sometimes have little pedagogical knowledge (Jenkins, Berman, \& Jenkins, 2005). It may be because of the labour market demand for the subjects like English and Information Technology. An analysis of the Labour Market Information Bulletins of Sri Lanka indicated that most job seekers are required to acquire the Information Technology and English proficiency that is expected by the labour market (Arunatilake \& Jayawardena, 2010). Those qualifications have been recognized as the pre-requisites for securing an employment in the corporate sector, whereas English is considered as the business language in the private sector in Sri Lanka (Wettewa, n.d.). On that premise, a common allegation is made against the ISs in Sri Lanka stating that the employment of under-qualified teachers in the schools in order to somehow fill the required number of teachers rather than considering the quality of teachers (Gamlath, 2013:47). Therefore, to overcome those issues and to obtain the service of trained and experienced teachers that are well conversant in English, the ISs have adopted the strategy of employing ETs who have been retired from the government school (Wettewa, n.d.; Jenkins et al., 2005).

\section{Research Method}

The study is mainly based on qualitative data primarily collected from the semi-structured in-depth interviews with the employers and principals of the selected private sector schools in Sri Lanka. Since this is quite a new area of research in the Sri Lankan context, usage of face-to-face semi-structured in-depth interviews allowed the interviewees to make some clarifications from the researcher before responding to questions and also the researcher had the opportunity to dig deep into certain areas where the school has special information regarding the employment of ETs. For data analysis purpose the study used "thematic analysis", which is "a method for identifying, analyzing, and reporting patterns (themes) within the collected data" (Braun \& Clarke, 2006:79)

The data collection was carried out with 9 interviewees (employers and principals) over a period of 4 months from January to April, 2015. The 9 schools have been selected from the Western province, which recorded the highest number of private sector schools in Sri Lanka. When selecting the schools, it has been taken into the consideration that a sufficient representation of both categories of schools (UPSs and ISs), whether the school employed ETs or not, and the size of the school in terms of student population. Therefore the study used the "purposive sampling" technique, where the units were selected based on specific purposes associated with answering the questions of the research (Teddlie \& Tashakkori, 2009:170). Those schools conduct classes from the primary level to the advanced level. Nonetheless, the scale of the selected school vastly varied from small to large in terms of the number of students and teachers, the standard of education, reputation, school fees, and the physical area and facilities provided. The 9 schools are categorized into three groups based on the number of students in the school. The schools with fewer than 500 students were under the small schools, the schools with a number of students between 500 and 3000 were under the medium and the schools had more than 3000 students were categorized as large. Accordingly the study considered 2 small, 3 medium and 4 large schools for the interviews. The 9 schools comprised 4 UPSs (including Catholic Management Board) and 5 ISs. Among the interviewees interestingly a half of them were retired government principals. A summary of the interviewed schools and the interviewees are given in the table 2 .

In the study a serious concern has been given to the ethical aspects of conducting the research, especially in collecting of data and publishing the findings. During the data collection stage, it was clearly communicated the interviewees about the researcher, the university, all of the contact details, and most importantly information about the current research through the official letter issued by the university authorizing the data collection and allowing them to decide whether to take part in the interview or not voluntarily. All of the nine interviews were conducted after getting their "informed verbal consent" and the interviews were held on the school premises. Also, depending on their preference, sometimes interviews were recorded and at other times notes were taken down. Protecting confidentiality is the most critical ethical concern of social researchers. Therefore, the confidentiality of the data would be kept without disclosing the names of the schools and interviewees when publishing the findings. 
Table 2. Summary of the Selected Schools and the Interviewees

\begin{tabular}{|c|c|c|c|c|c|c|c|c|c|c|c|c|c|}
\hline & $\begin{array}{c}\text { School } \\
\text { Type }\end{array}$ & $\begin{array}{c}\text { Size of } \\
\text { School* }\end{array}$ & Location & $\begin{array}{l}\text { Single } \\
\text { sex or } \\
\text { Co-ed }\end{array}$ & Curriculum & $\begin{array}{c}\text { No. of } \\
\text { Students }\end{array}$ & $\begin{array}{c}\text { No. of } \\
\text { Teachers }\end{array}$ & Interviewee & Age & Gender & Education & $\begin{array}{c}\text { Working } \\
\text { Experience }\end{array}$ & $\begin{array}{c}\text { Service } \\
\text { in school } \\
\text { (years) }\end{array}$ \\
\hline 1 & IS & $\mathrm{S}$ & City & Co-ed & National & 250 & 30 & Chairman & 45 & Male & Post graduate & Educationist & 9 \\
\hline 2 & IS & $\mathrm{S}$ & Suburban & Co-ed & $\begin{array}{c}\text { National \& } \\
\text { British }\end{array}$ & 350 & 40 & Principal & 63 & Female & Diploma & Educationist & 6 \\
\hline 3 & UPS & M & City & Single & National & 1650 & 76 & Principal & 72 & Female & Post graduate & Educationist & 28 \\
\hline 4 & UPS & M & City & Single & National & 2900 & 130 & Principal & 63 & Female & Post graduate & Educationist & 2 \\
\hline 5 & IS & M & Suburban & Co-ed & National & 2500 & 255 & $\begin{array}{l}\text { Managing } \\
\text { Director }\end{array}$ & 76 & Male & Post graduate & Educationist & 15 \\
\hline 6 & UPS & $\mathrm{L}$ & City & Single & $\begin{array}{c}\text { National \& } \\
\text { British }\end{array}$ & 6700 & 330 & Principal & 67 & Female & Post graduate & Educationist & 7 \\
\hline $7 * *$ & IS & $\mathrm{L}$ & City & Co-ed & $\begin{array}{c}\text { National \& } \\
\text { British }\end{array}$ & 5000 & 600 & Principal & 41 & Female & Post graduate & Educationist & 10 \\
\hline $8^{* *}$ & IS & $\mathrm{L}$ & City & Co-ed & $\begin{array}{c}\text { National \& } \\
\text { British }\end{array}$ & 15500 & 1700 & Directress & 52 & Female & Post graduate & Educationist & 22 \\
\hline $9 * * *$ & UPS & $\mathrm{L}$ & City & Single & National & 42500 & 2100 & $\begin{array}{l}\text { General } \\
\text { Manager }\end{array}$ & 51 & Male & Post graduate & Educationist & 9 \\
\hline
\end{tabular}

* Size of school: S- Small school M- Medium school L- Large school

**Schools with branches

*** Collection of Catholic schools

\section{Reasons for Employing ETs in the Private Sector Schools in Sri Lanka}

The 9 interviewees in the study representing 9 private sector schools mentioned that their schools are willing and currently employing ETs and elaborated reasons as to why they have employed ETs in the schools. According to the interviewees, due to the higher dominance and recognition of the government-driven school education sector in Sri Lanka and the availability of few private teacher training institutes, still the term "trained/qualified teacher" is often used and accepted in the society for those that undergo the government teacher training. Though there are reputed and well-paid private sector schools in Sri Lanka, it is always the individual's choice of prioritizing the government sector permanent teaching employment over private school teaching, which provides them with comparatively higher recognition, many benefits, and job security. They can earn a higher salary, employment status, a higher level of freedom, autonomy, job security, entitlement to a pension, and a higher leave entitlement, all of which are some of the key factors. Therefore, as mentioned by the interviewees, one of the main challenges that private sector schools are facing today is to hire trained/qualified teachers.

\subsection{Shortage of English Medium Qualified Teachers, Especially for Upper Classes}

With the enactment of the "Swabhasha Policy" (Sinhala language only) in 1956, the government of Sri Lanka promoted vernacular language (Sinhala language) as the medium of instruction in the education system, which in turn drastically downgraded the importance of English education. Though English was taught as a separate subject, infrequent usage of English language made it less familiar to the students and teachers in the later generations. Consequently, the teachers were trained in the vernacular language and therefore it was difficult to find qualified teachers that could teach other subjects in the English medium, especially for the upper classes.

The interviewees stated that qualified teachers can be found in the system, but they are not proficient enough to deliver subjects in the English medium, which is a main requirement of ISs. Not only that, the interviewees from the UPSs also mentioned that there are teachers that are willing and capable to teach in their schools but only in the vernacular language (Sinhala medium). In the absence of qualified English medium teachers, as an alternative method currently private sector schools are employing ETs that can deliver subjects in the English medium. Some of the interviewees concerns were as follows:

One of the main issues international schools are facing is lack of English medium qualified teachers. (Interviewee 4) 
Qualified teachers are in the school education system. But the problem is the language barrier (English proficiency).Until we find a better solution we have decided to employ retired teachers who can teach in English medium. (Interviewee 1)

An interviewee representing an UPS shared her experience about the upcoming trend of increasing number of students that are following national curriculum in the English medium. Earlier, in her school the number of classes in the Sinhala medium was greater. At present, the number of English medium classes is higher than the Sinhala classes and this will further rise. This is an indication for the education system that more English medium teachers will be needed in near future.

Earlier we had many Sinhala medium classes. But now English medium classes exceeded that number. This trend will be further escalated, which means we need more quailed English medium teachers. (Interviewee 4)

This issue was aggravated when teaching subjects like English literature, English language, mathematics, science, chemistry, and physics in the upper classes. The interviewees mentioned that, unlike the primary and lower grade classes, some of these subjects are usually somewhat technical in terms of conceptualization, usage of proper terminology, and also explanations and knowledge transfer consumes considerable time comparatively. On the other hand, it is sometimes challenging for the students in the English medium classes when going through the textbooks in English and therefore the students expect greater support from the teachers. This may be partly due to prevailing "teacher-centered" school education system in Sri Lanka. Considering the nature of certain subjects and the hardships that the students are undergoing, it can be argued that the interest in the subject and proper knowledge transfer in the English medium would highly depend on the teaching ability of the instructor. Thus, the unavailability of qualified teachers would sometimes compel them to rely on ETs, disregarding their age and retirement status, as can be seen in the following passage from one of the interviewees:

We do not have sufficient number of English medium qualified teachers, particularly for upper class subjects such as Science, English Literature, Physics, and Chemistry. Only available solution at the moment is to get the service of retired teachers. (Interviewee 7)

One interviewee described her experience in hiring an English medium physics teacher for an Advanced Level class as follows:

The school had to advertise thrice the vacancy for Physics teacher. Young candidates applied but they did not like to work on full-time basis, knowing they can earn much by conducting private tutoring for the students. So, finally we ended up with a retired teacher. (Interviewee 6)

Her explanation of advertising one vacancy thrice in order to select a proper candidate for a particular subject and yet the unavailability of young candidates led them to finalize with an ET is an indication of the shortfall of teachers. Also, it is a depiction of the fact that a difficult subject like physics is in demand for teachers in the education market. Though young teachers are found (for an example, science graduates from the universities), they are hesitant to commit to the schools on a full-time basis since they can find better opportunities as part-time tutors. However, such an arrangement is not appropriate for schools because they are looking for a teacher that is completely responsible for the subject rather than a part-time tutor. Sometimes upper class students need to frequently contact the teacher when they have questions or need clarifications. Further, the teacher is supposed to be accountable for the results of the students, which eventually is an inevitable part of the image of the school. Increasing trend of English school education system and inadequacy of English medium teachers in the system encouraged private sector schools to hire ETs.

\subsection{A Dearth of Teachers with Required Pedagogical Knowledge}

Having realized the vitality of pedagogical knowledge, the interviewees always oblige to hire teachers with both the subject knowledge and thorough pedagogical knowledge. Pedagogical knowledge is improved through proper training and experience that teachers have with the passage of time. Many interviewees admired the training received by the government teachers and were concerned about the lack of such opportunities available for private sector teachers, who tended to think that government-trained teachers (including retired teachers) are sound in class management, student evaluation, and lessons planning and implementing. Further, their involvement in the national examination evaluation (Ordinary Level and Advanced Level paper evaluation) would also be an additional advantage for the school. According to the employers, one way of acquiring such a vast knowledge base for the private sector schools is to recruit ETs, as one interviewee explained: 
I like to get the service of ETs. Because their training and experience do not reflect any doubt about their subject knowledge and pedagogical knowledge. Knowledge imparting is one role of a teacher. Beyond that, class management, lesson planning, tools for evaluating students, understanding uniqueness and diversities among the students, developing habits of mind and motivating students towards learning which are developed over the time along with the maturity of a teacher. (Interviewee 8)

The interviewees were satisfied with the English language proficiency and subject knowledge of young teachers. Yet, they said that younger teachers were developed in subject specialized areas while their overall teaching knowledge and management of the classroom was limited. Hence, the interviewees were of the view of that the younger teachers in the private schools sometimes lacked the required pedagogical knowledge due to their training deficiencies and having less experience. Thus the schools were hesitant to assign complete subject responsibility and class room management to fresh young teachers. Rather, young teachers would be kept under the guidance and supervision of senior or mature teachers for a specified period. In such circumstances, again the demand was higher for ETs, who can play a bigger and more confident role for the satisfaction of the school administration, as seen in the following passage:

We have good young teachers. But we are afraid of assigning them complete responsibility of a class room because they are specialized in subject knowledge, but limited pedagogical understanding. They need further pedagogical developments. Therefore, sometimes we provide them training and other times they work with senior teachers. (Interviewee 4)

This indicated that employers are not quite satisfied with the pedagogical knowledge of the young teachers in the private sector schools and are taking measures to improve it. This situation may partly be due to the lack of training for the teachers in the private sector schools and sometimes quick and ad hoc teacher recruitment practices cause the problem. As to mitigating those issues, some of the schools have decided to get the services of ETs, who are pedagogically sound and can gradually guide and groom young teachers with the required knowledge.

\subsection{Frequent Job Attrition among Young Teachers}

As mentioned in the interviews, the private sector schools prefer to employ young teachers. There are also young English-conversant graduate and non-graduate teachers that are willing to teach in the private sector schools. Some of the young teachers join private sector schools because they got a government teaching appointment in a remote area where they would not want to be far away for various reasons. However, the issue is the retention of such teachers in the private sector schools. Some interviewees said that job attrition among the young qualified teachers was much high, since they are frequently looking for better prospects and changing schools. The increasing number of private schools in Sri Lanka and the rising competition generate ample opportunities and a higher demand for the younger teachers with lucrative packages, as one of the interviewees suggested in the following:

Young graduate teachers who got government appointments in remote areas would like to join in international schools in Colombo. But their retention is the problem. They are more concerned about the financial benefits and reputation of the schools. (Interviewee 8)

From the perspective of the small IS it was claimed that job attrition was higher in their schools. After getting some experience from small schools, usually they shift to another school. One interviewee representing a small IS mentioned that "the school has become a training center to provide experience for young teachers." That statement itself reflects how challenging it is to retain young teachers for the school. The frequent changing of teachers affects the studies of the students and makes them uncomfortable in terms of re-adjusting. Thus, sometimes parents complain about it to the school administration. It is not good for the reputation of the school either. According to interviewee 4, "some young teachers stay only for 2-3 months. Again new teacher comes. This is difficult for students. Parents are very unhappy about it and complain."

Thus, many schools prefer to have young teachers, yet youngsters are often shifting schools for various reasons, which adversely affects the students and the school administration. That problem cannot be arisen among the ETs, making employers to have confidence in them.

\subsection{Competence of Elderly Teachers}

The interviewees have evaluated the competence of ETs in terms of knowledge, vast experience, and quality of academic work. All the interviewees of the study unanimously stated that one of the main reasons they would like to employ ETs in the private sector schools was their subject knowledge and vast experience in the government sector schools. Many of the interviewees in the study (6 out of 9) are retired government principals and they have endorsed 
this fact with much confidence in ETs. Interviewee 4 stated that "since I worked in several government schools, without any reservation I can recruit government retired teachers, knowing how competent they are."

This endorsement was further supported by the government training undergone by the government teachers. It has earned such an importance because of the majority of private sector teachers have limited access to teacher training. Knowing this fact, the interviewees (especially those who came from government schools) would like to get the service of ETs. Another interviewee (a retired principal from a government school) commented about the competence of ETs' referring to her experience as a government trainee teacher was as follows:

I have no doubt about the competency of the elderly teachers. The training government teachers are given is a solid foundation for teaching career in the Sri Lankan education system. It begins from the scratch. I was a trainee a long ago. (Interviewee 2)

One interviewee from other than a government school background also shared his experience, distinguishing the competence of ETs from government schools and teachers from a different background. His observation was about the "quality of academic work" in terms of designing the syllabus, lesson planning, and developing learning materials, which reflected the expertise and experience of ETs. Sometimes he used those materials as examples for other teachers to compare with their materials. It is the pedagogical expertise that is partly developed through training and partly with experience, as stated in the following:

A clear distinction can be identified in the quality of work between the experienced retired teachers and other teachers. I mean government teachers are far ahead in developing syllabus for different grades, lesson planning and developing learning materials. That is their maturity in the profession. (Interviewee 1)

This may be due to the recognition acquired by the government school education system in Sri Lanka, being the dominant education provider to the nation and the quality it maintains throughout the history in terms of academic achievement and producing all-round students for the society. The main role players behind that success are the teachers.

\subsection{Elderly Teachers as Administrators}

For the smooth operation of the school having a good team of administrators is inevitable. Being in the teaching profession for a long time, ETs have been groomed with a lot of exposure in dealing with a variety of academic and administrative matters. By employing them in private sector schools, it is expected that they will make use those capabilities. The interviewees mostly wanted to hire ETs as "sectional heads" of the schools. This was mentioned by both the UPSs and ISs, because they believed that the person that is supposed to hold that position should be "an experienced senior teacher." One interviewee stated that sometimes the alumni members of the school suggested to the board of management in the school to re-employ retired teachers for certain administrative positions. This is because of the commendable service that those teachers made to the school and the past students retained memory of this. As interviewee 6 stated, "sometimes alumni association suggests to re-employ retired teachers whose service was good during their times."

Further, some of the interviewees described the support extended by the ETs as mature decision makers by bringing different perspectives to the decision table. Formal and informal networks they have built so far with education professionals, alumni members, and ministry officials are very much useful in many instances when the school needs external support. For example, one interviewee mentioned that when organizing seminars for teachers or students, the resource persons were introduced through the contacts of ETs. This was described by interviewee 3 as follows: "there are several senior (elderly) teachers who are voluntarily organizing seminars for teachers with their own contacts with the resource persons."

ETs are good at grievance handling and in complaint management areas, as the sectional heads. They carefully handle grievances from the teachers as well as from the parents. It is quite a challenging and time consuming task. The tactics used in those situations are different from teachers to parents. It is obligatory to pay attention to those issues and to provide some solutions for better operation of the school. According to the interviewees, qualities such as understandability, patience, and listening ability are powerful tools among the ETs to negotiate or to provide solutions for the satisfaction of the related parties. Interviewee 4 mentioned that "as the principal of the school, it is impossible for me to attend all those complaints. So I am grateful for senior teachers who are shouldering those responsibilities on behalf of the school."

The private sector schools would like to obtain the service of ETs for administrative positions in addition to their role as teachers whenever it is possible to utilize their different skills. From the school aspect, it is a better option for 
hiring retired teachers for the sectional head positions. However again from the point of younger teaching staff, it may be disadvantageous for them by limiting the career advancement opportunities available to them. In other words, rather than filling those positions from the available young teachers and employing ETs might lead to dissatisfaction among the young teachers.

\subsection{Elderly Teachers as Mentors}

In the absence of many training opportunities and induction programmes for young and novice teachers in the private sector schools, would inevitably underscore the necessity of providing the support and guidance from an experience teacher. With that premise, the interviewees would like to assign the role of "mentor" to the ETs, considering their long service and wide experience. It was revealed that in the private sector schools in Sri Lanka, have not officially given the role of mentor to ETs; sometimes it is given as an additional responsibility. The way it works in the school is that, sometimes the school administration requests the ETs to serve as a mentor by having a few young teachers under their guidance and support. Though no special allowance is paid for this task, the ETs would consider it is as a privilege or an honour. Mainly the ETs assist the younger teachers being better prepared for classroom work, setting realistic targets, maintaining records, meeting deadlines, handling student affairs, and confidence building.

It is interesting to note that some of the ETs are passionate about sharing their experience and supporting young teachers while doing their regular teaching, without any request from the school administration. Nevertheless, this voluntary mentoring arrangement depends on the interest and mutual understanding of the young and elderly teachers. Hence, that act itself exemplifies the "professional responsibility" of ETs towards the younger generation. This was praised by interviewee 1: "volunteer mentoring is an admirable quality among the elderly teachers. Perhaps it may be part of our cultural values, where seniors nurture the juniors."

Other interviewees mentioned that young teachers too have positive reactions towards senior mentors. This is because sometimes they consider ETs as their "role models or leaders" and would like to follow their foot-steps and get advice from them. This shows the commitment and open-minded characteristics of the young teachers that are aspiring to advance their career. The ETs know how to track the progress of the teachers that are under their supervision by observing them on a regular basis. Their mentoring ability is very particular, and even minor mistakes are rectified as can be seen in the following passage:

As an example, some young teachers do not much concern about putting the date on the white board as a routine practice before they start the class and thus the same practice is followed by the students as well. Apparently it seems a minor a mistake but the significance of such a regular practice is immense. (Interviewee 3)

In analyzing the mentor-mentee arrangement between the elderly and younger teachers, it can be seen that it does not only serve as a development mechanism in the school, but also it serves as a useful platform for creating a "healthy relationship" between the two generations. Working together cooperatively would enhance the understanding and mutual respect between them and provide lessons for the student community in the school. The students also can see the way that young teachers are dealing with the ETs and they will be compelled to do the same. Perhaps this relationship may be a strong measure for eliminating elderly-related stereotypical beliefs from the labour market, because constant working relationship between the younger and elderly teachers would pave the way for understanding the actual behaviours of elderly rather than assuming elderly working behaviours and characteristics.

\subsection{ETs as Guardians of School Culture or Disciplinarians}

Some of the interviewees identified the potentials and values ingrained in the ETs to foster a "value-driven culture" in the school environment, which is an essential part of the education system. This objective has been officially mandated in every school and it is included in the school curriculum as well, abided by the school management, teachers, students, alumni, and parents. The schools in the study reflected different types of cultures: a particular religion-driven culture (for example, Buddhist philosophy, Catholicism) and multi-ethnicity. The interviewees believed that, among other things to protect and maintain a unique school culture, ETs can play a key role as "guardians" of the culture because of their seniority (in age and the position), long-standing experience, and earned respect over the time. This is not an idea merely from the interviewees, but they have confirmed that the rest of the stakeholders too unanimously had admitted the same in various instances, as stated in the following:

It is unanimously agreed by the management, teachers, parents and alumni, the significance of having several retired teachers from the (same) school as guardians of unique culture of the school, whom can proudly share the history, symbols and values of the school. (Interviewee 9) 
The above statement was expressed by an interviewee representing Catholic schools, who emphasized the significance of grooming the students academically and religiously. He stated that the overarching religious and historical values in the school bring a set of disciplines to the students, which will have a long-lasting impact on the students. The exact story tellers for this purpose are those that have been with the school for several decades and that can transmit that reality into the minds of the students. He further said that "in that sense, the right person is a teacher who has served in the school for a long time."

Another interviewee said that sometimes the guardian role was one of the grounds for extending the service of teachers that have reached the retirement age. Usually the alumni of the school also favourably influence the making of such a decision. Being in that school culture for a long time may be as a student and then as a teacher, and these individuals are the most familiar with the school culture and they can help new students and young teachers to understand and socialize with the unique culture of the school. Interviewee 6 explained that "the school prefers to extent the service or to get re-joined retired teachers from their own school. Sometimes such suggestions are coming from the alumni association of the school as well."

In that sense the demand for employing ETs is a cooperative decision. Their service has been acknowledged not only the demand from the employers but also by the other stakeholders of the school as well. This is a clear reflection of having the positive attitudes towards the ETs in the private sector schools in Sri Lanka.

\subsection{Less Reputation of Newly-Opened International Schools}

As per the elaboration made by the some interviewees, at the early stage of the school, it is difficult to attract students and teachers without establishing the name of the school and also without having sound evidence to prove academic and other performances. Similarly, within a short period of time, coupled with a limited number of students in a small school, sometimes it is impossible to showcase better academic and extracurricular performance. Hence, at the beginning, those schools are not in a position to earn a higher reputation in the education sector in comparison with the well-established schools. Usually, it takes some time to reach the stability. The competition among the schools adversely impacts those schools due to their newness, small size, and limited resource base. As a result, recruiting teachers has become a challenging task for new and small schools, especially young qualified teachers, whose demands and career expectations are quite high and they perhaps may look for opportunities in popular schools. However, the absence of qualified teachers in the schools again exacerbates the issue of gaining the reputation of the school, and increasing the student enrolment and improving performance. Therefore, the employers from new and small ISs thought of tapping the alternative strategy of employing ETs. The reasons described by the interviewees for choosing them are: ETs are qualified and experienced and at the same time they are not much concerned about the reputation of the school. A principal of a new IS explained her concerns about the school and how she managed to overcome some of them in light of recruiting ETs.

As a newly-established school, we have lots of challenges such as increasing student enrolment, promoting the image of school, earning sufficient income, competition from other schools and etc. As one of the alternatives to face those challenges, it is crucial to have qualified teaching staff in the school. That is why our school thought of attracting qualified retired teachers whom are not much bothered about the reputation of the school. (Interviewee 2)

The above excerpt highlights the difference between the two generations in choosing employment opportunities. When searching for these opportunities, ETs are not really particular about the reputation of the school, unlike younger teachers. However, this does not underestimate the decision of ETs in choosing an unpopular school, because for the ETs this may be their second/alternative career after the retirement. Therefore, rather than employing in a popular school, sometimes ETs may prefer joining a new and small school, where they can contribute much for further development of that school. However for the younger teacher, it may be his or her start-up career and he or she may be looking forward to making a long journey and thereby consider the reputation of the school. This revealed the "objective differences" among the two groups.

\subsection{Financial Constraints of the Schools}

At the beginning of a private school and also if it is small in size, financial obstacles are unavoidable. The main source of income for UPSs and ISs is the school fees paid by the students. If the number of students is low, then the income received is insufficient to meet all of the school expenses. Therefore, schools tend to be concerned about the payroll budget when making hiring decisions. Sometimes new and small ISs are compelled to recruit qualified ETs because their "expectations" can be matched by the school. This has been further elaborated by the interviewees, who indicated that expectations mean not lower remuneration but often ETs prefer engagement in teaching only, 
flexibility or part-time employment, and less extra-curricular involvement. On the other hand, if the school wants to hire a young qualified teacher, he or she can serve on full-time basis yet the salary expectations are higher. Considering the constraints faced by the schools they would go ahead with ETs by negotiating favourable terms and conditions that are beneficial for both the school and ETs. Some of the comments in this regard are as follows:

Like reputed international schools we are not in a position to meet the higher expectations of younger qualified teachers. So we always prefer to have retired teachers whom have negotiable expectations. (Interviewee 1)

In the selection interview, often retired teachers expressed their enthusiasm of continuing teaching career rather than benefits and other demands. (Interviewee 2)

In essence, the underlying argument behind financial consideration is that schools (especially new and small ones) prefer to employ ETs as they can get their service for lower remuneration. That is the hidden meaning of "difficulties in meeting higher expectations of younger teachers." This implies several concerns regarding elderly employment and private-sector school education. The positive side of this measure is that somehow ETs manage to be re-employed after their retirement. The ETs draw a pension and this is for them an additional income or a mean of active engagement, and employers take advantage of this to negotiate the remuneration while offering other comforts.

From the education perspective, there is a compromise in the quality of education in new and small schools. Offering ETs a lower salary means perhaps that they may compromise their dedication and contribution to the school. Especially flexibility in their time table may compel higher absenteeism, less punctuality. Hence, the school has to take those things into consideration.

\section{Discussion}

As mentioned by the employers from the private sector schools in Sri Lanka, the shortage of teachers was specifically found in the areas of English medium-qualified teachers for the upper classes and teachers with adequate pedagogical knowledge. Apart from that job attrition among the young teachers caused to further elevate the teacher shortage. Whatever may be the reasons, the ultimate impact of teacher shortage poses a threat to the quality of education in the private sector schools. Teacher shortages are prevalent not only in developing countries, as the OECD report (2011) has mentioned that many of the advanced economies too face the same issue, because of the rapid ageing of the teaching workforce and the high rates of attrition among new teachers. Further, the shortage will increase in the near future as large numbers of teachers reach retirement age.

In the case of Sri Lanka, the recent introduction of an English-medium curriculum and the growing trend in number of ISs have demanded higher numbers of English-medium qualified teachers for upper classes, especially for subjects such as English language, English literature, science, mathematics, and IT. A study of Nunun (2003:607) stated that, after studying 7 countries in the Asia-Pacific region: "English language proficiency of many school teachers is not sufficient to provide learners with the rich input needed for successful foreign language acquisition".

Having realized the teaching cadre requirements in the schools in Sri Lanka, it is necessary to supply a sufficient number of qualified teachers for the system either through the government or private training institutes. However, in the absence of adequate English teachers for the government schools (Hettiarachchi, 2013; Thirunavukkarsu, n.d.), it is unlikely to expect the government to fulfill the private sector teaching cadre requirements.

Lack of pedagogical knowledge among the young teachers in the private sector schools in Sri Lanka is another reason for employing ETs. The reason for relying on ETs is the government training they have undergone and their experience throughout the teaching career, made them pedagogically sound. Sometimes private sector schools tend to give priority for the English language proficiency of teachers over their pedagogical knowledge in hiring of teachers. However, it is doubtful that those young teachers will be able to undergo proper pedagogical training even at a later stage amidst of the lack of opportunities and budgets available for teacher training in the private sector schools. As an example, some schools directly hire graduates that have subject knowledge but not pedagogical knowledge. A study researching science teachers' pedagogical content knowledge identified teaching experience as the major source of pedagogical content knowledge, whereas adequate subject-matter knowledge appeared to be a pre-requisite (Van Driel, Verloop, \& de Vos, 1998). As a partial solution to the pedagogical issue among the young teachers, private schools can utilize ETs. However, in the long run, it is imperative to develop the pedagogical knowledge among the young teachers unless knowledge impartation is defective, especially for the students that are learning difficult subjects in English, which is the second language in Sri Lanka. This may generate a knowledge gap 
between the students that study the same syllabus in the vernacular language (Sinhala) and the second language (English).

Another major challenge of private sector schools in Sri Lanka is frequent job attrition among the young teachers, especially among the small schools, persuading the schools to rely on ETs. The causes of attrition were the following: higher demand for young teachers, lucrative financial and non-financial benefits offered, less reputation in the small schools, limited career advancement, and lack of accountability towards the current school. Nonetheless, job attrition incurs huge replacement costs and also frequent changes of teachers negatively affect the students and the image of the school.

Job attrition can be explained through the human capital theory of occupational choice, which stated that individuals make systematic assessments of the net monetary and non-monetary benefits from different occupations and make systematic decisions throughout their career to enter, stay, or leave an occupation (Kirby \& Grissmer, 1993). Thus, an employee calculates the accumulation of human capital and converts it into wage premiums. Accordingly, the greater the capital accumulation in a particular organization, it is more unlikely the employee will leave the organization. That theory provides an adequate explanation for higher attrition at the early stage of career rather than mid or late career.

Ingersoll (2001) conducted a statistical analysis comparing private and public school teachers longitudinally and revealed that large private schools experienced the lowest average turnover rate, and small private schools had the highest. The similar finding was confirmed by the current study revealing that, mostly the small private sector schools suffer from job attrition in Sri Lanka. The issue of younger teacher attrition in the inner-city schools in the U.S.A. and its associated teacher replacement costs, and the effect for children educational outcome has been studied (Martinez et al., 2006). Considering the consequences, the authors suggested that one of the alternatives was to get the support of retired/ elderly teachers on voluntary basis. Further the study revealed that how job attrition could be prevented by employing retired teachers as a useful source of giving emotional support to young teachers in order to increase job satisfaction and to reduce absenteeism of young teachers, ultimately improving the quality of education delivered by satisfied young teachers.

Additionally the employers in the private sector schools in Sri Lanka prefer ETs over younger teachers because of their competency and other expertise contribution such as administrative capability, mentoring skills and school guardian/disciplinarian roles played by the ETs. It has been stated that teacher education and teaching experience have most often been used to measure teacher competence (Myrberg \& Rosén, 2004:2).

The life cycle of the career teacher explains six progressive phases of teaching career along a continuum from novice, apprentice, professional, expert, distinguished to finally emeritus teacher (retired but continue to contribute to the profession) (Steffy, Wolfe, Pasch, \& Enz, 2000). Following the retirement, many career educators choose to honour their lifelong commitment by serving the profession in alternative roles, such as administrators, consultants, volunteers, mentors, and advocates. As theory suggested, sometimes ETs are offered employment opportunities by the private sector schools in Sri Lanka in order to obtain this additional expertise. Many of the studies found that, those expertise roles of the ETs are admired by employers, young teachers, and parents. In the study of Goddard and Habermann (2001) it was found that when establishing formal mentoring programmes for novice teachers, an innovative strategy was utilizing the skills and knowledge base of retired teachers so as to obtain their service as mentors. Another study described numerous ways of retaining teachers, facilitated by the retired educators and older volunteers in terms of educating newer teachers regarding school expectations, identifying problems faced by new teachers, and suggesting solutions, imparting classroom management skills, providing both instrumental and moral support, improving novel teacher satisfaction, and playing an important role in bringing together teachers and parents in a partnership that fosters greater parent involvement (Martinez et al., 2010).

Another vital role that the private sector schools were expecting from the ETs was to serve as guardians of the preserved values of the school culture and to help maintain students' discipline. Schools should take initiatives for the life enrichment of the students through elderly teachers' intervention, beyond the formal educational support from the ETs. As revealed in the current study, endorsement comes from many other stakeholders, such as the school administration, and parents and alumni. This does not mean that the young and new teachers in the school are incapable of cultivating that environment. However, age and seniority explicitly play a dominant role in Asian culture, where a high degree of deference is shown toward the elderly (Kim \& Mo, 2014; Bond \& Hwang, 1986).

The employers from new and/or small schools considered the option of employing ETs due to the financial constraints. However, it was an indication of that, the service of ETs can be obtained at a lower salary. In the survey of Bittman et al. (2001) discussed the same issue of financial pressure under the special needs of small organizations 
that are operating with lower overhead and profit margins yet striving hard to be competitive. Hence the schools compromise the benefits with the ETs under the different employment terms and conditions such as offering flexible employment, releasing ETs from extra-curricular activities. Nevertheless, lower financial incentives cause the deterioration of the quality of education provided by less-motivated ETs and in turn that can make a huge damage to the students and the reputation of the school. Nonetheless, the findings of the study highlighted the numerous entry paths that the ETs can contribute in the education labour market and the opportunities available for ETs.

\section{Conclusion}

The study was purporting to examine as to why do private sector schools in Sri Lanka employ ETs. Accordingly, the research findings revealed that ETs have opportunities in the private sector schools in Sri Lanka and employers/principals would like to employ ETs due to various reasons.

The shortfall of English medium qualified teachers especially for upper classes and lack of teachers with sound pedagogical knowledge compelled to hire ETs in the private sector schools. Further, the private sector schools prefer to recruit young teachers yet frequent job attrition among them created the issues for the students and school administration. However, employers/principals perceived that employing of ETs would not make job attrition problems in the schools. Moreover, all the interviewees unanimously agreed upon the competence of ETs as one of the major reasons for hiring the ETs. Despite that, the expert contribution that the ETs can provide to the schools as administrators, as mentors to groom young teachers and also guardian role for preservation of the school culture are pivotal motives for recruiting the ETs. The expertise support of the ETs has not only been endorsed by the employers/principals of the schools but the young teachers, alumni and parents. Additionally, newly opened and/or small-size schools mentioned particular reasons for hiring the ETs were less reputation of those schools and the financial constraints.

It was empirically evident from the study that under various grounds the private sector schools would hire the ETs and this trend would be a progressive step that has been taken by the employers in the private school system amidst of rapidly rising ageing population in Sri Lanka. Welcoming them back to the labour market is beneficial for both the schools and the ETs as well. It can be considered as an appreciation of elderly wisdom without treating older people as a burden to the society. Moreover, the interaction of ETs with young teachers and children can mitigate the generational gap and lead to inculcate favourable attitudes towards ETs, which is a timely necessity. Therefore, the other professions/sectors which undergo labour shortage can also adopt the strategy of employing elderly employees as an alternative solution.

The implications that arise from the shortfall of teachers in the private sector schools are multiple. Profoundly it is needed to increase the supply of qualified teachers. Retirement is one main path of leaving qualified teachers from the schools. As currently informed and implemented by the private sector schools in Sri Lanka, employing ETs is one of the common strategies for managing the shortage. Despite that, developing young teachers with adequate knowledge and skills, making the teaching profession more lucrative in terms of benefits and career prospects is another way of attracting and retaining young qualified teachers in the system. Taking immediate initiatives in those areas are critical in order to ensure the quality of education provided by the private sector schools in Sri Lanka.

\section{Acknowledgment}

The author would like to kindly acknowledge the constructive comments provided by Professor Suchitra Punyaratabandhu of Graduate School of Public Administration, National Institute of Development Administration (NIDA), Bangkok, Thailand.

\section{References}

Arunatilake, N. \& Jayawardena, P. (2010). Explaining Labour Market Trends Imbalance in Sri Lanka. In R. Gunatilaka \& M. Mayer, M. Vodopivec (Eds.). The Challenge of Youth Employment in Sri Lanka, (pp. 96-88). The World Bank.

Balasooriya, B. M. J. (2013). Teacher Recruitment and Teacher Mobility in Sri Lanka, Commonwealth Education Partnerships. Retrieved

from http://www.cedol.org/wp-content/uploads/2013/09/Teacher-recruitment-and-teacher-mobility-Balasorriya.pdf

Bal, P. M. \& Visser, M. S. (2011). When Are Teachers Motivated to Work Beyond Retirement Age? The Importance of Support, Change of Work Role and Money. Educational Management Administration \& Leadership, 39(5), 590-602. http://dx.doi.org/10.1177/1741143211408448 
Bittman, M., Flick, M., \& Rice, J. (2001). The recruitment of older Australian workers: A survey of employers in a high growth industry (Final report prepared for the Department of Family and Community Services). Social Policy Research Centre, Australia. Retrieved from; https://www.sprc.unsw.edu.au/media/SPRCFile/Report6_01_Recruitment_of_Older_Workers.pdf

Bond, M. H., \& Hwang, K. (1986). The social psychology of Chinese people. In M. H. Bond (Ed.). The psychology of the Chinese people, (pp. 213-266). New York: Oxford University Press.

Botwinik, R., \& Press, M. R. (2006). Career options for retired teachers. The Clearing House, Heldref publications. http://dx.doi.org/10.3200/TCHS.79.3.145-146

Braun, V., \& Clarke, V. (2006). Using thematic analysis in psychology. Qualitative Research in Psychology, 3(2), 77-101. http://dx.doi.org/10.1191/1478088706qp063oa

Fyfe, A. (2007). The use of contract teachers in developing countries: Trends and impact. (Working paper, Sectorial activities programme). Geneva: ILO.

Gamlath, S. (2013). Freeing free education in Sri Lanka. Asian Education and Development Studies, $2(1), 34$ - 52. http://dx.doi.org/10.1108/20463161311297617

Goddard, J.T., \& Habermann, S.R. (2001). Accessing the knowledge base of retired teachers: experiences in establishing a formal mentoring program in a rural school division. Journal of Research in Rural Education, 17(2), 92-101.

Hettiarachchi, S. (2013). English language teacher motivation in Sri Lankan public schools, Journal of Language Teaching and Research, 4(1), 1-11. http://dx.doi.org/10.4304/jltr.4.1.1-11

Hettige, S. T. (2005). Shifts in the educational structure of Sri Lanka following economic liberalization (Report No.3). Institute of Education, University of London.

Human Development Report Sri Lanka. (2012). Retrieved from http:/www.lk.undp.org/content/dam/srilanka/docs/localpublications/Sri\%20Lanka\%20Human\%20Developmen t\%20Report\%202012.pdf

Ingersoll, R. (2001). Teacher turnover, teacher shortages, and the organization of schools. American Educational Research Journal, 38(3), 499-534. http://dx.doi.org/10.3102/00028312038003499

Jenkins, K., Berman, J., \& Jenkins, B. (2005). A Proliferation of Self-described 'International' Schools in Sri Lanka: A Response to Globalization. Questioning, 1, 112-128.

Kim, D.S., \& Mo, S.H. (2014). Stereotypical beliefs on old Korean workers. Ageing International. http://dx.doi.org/10.1007/s12126-014-9200-4

Kirby, S. N., \& Grissmer, D. W. (1993). Teacher attrition: Theory, evidence, and suggested policy options. Information Analyses. Santa Monica, California: Rand Corp.

Little, A.W., \& Hettige, S.T. (2013). Globalization, Employment and Education in Sri Lanka: Opportunity and division. Oxon: Routledge.

Luekens, M. T., Lyter, D. M., Fox, E. E., \& Changler, K. (2004). Teacher attrition and mobility: Results from the Teacher Follow-Up Survey, 2000-01.Washington D.C.: U.S. Department of Education.

Martinez, I.L, Frick, K.D., Kim, K.S., \& Fried, L.P. (2010). Older adults and retired teachers address teacher retention in urban schools, Educational Gerontology, 36(4), 263-280. http://dx.doi.org/10.1080/03601270903212302

Myrberg, E., \& Rosén, M. (2004). The Impact of Teacher Competence in Public and Independent Schools in Sweden. Retrieved from http://www.iea.nl/fileadmin/ user_upload/IRC/IRC_2004/Papers/IRC2004_Myrberg_Rosen.pdf

Nunun, D. (2003). The impact of English as a global language on educational policies and practices in the Asia-Pacific region, TESOL Quarterly, 37(4), 589-613. http://dx.doi.org/10.2307/3588214

Organization for Economic Cooperation and Development. (2011). Building a High quality Teaching Profession. Lessons from around the world (Background Report for the international summit on the teaching profession). Retrieved from https://www2.ed.gov/about/inits/ed/internationaled/background.pdf

Redman, T., \& Snape, E. (2002). Ageism in teaching: Stereotypical beliefs and discriminatory attitudes towards the over 50s. Work, Employment and Society, 16(2), 355-371. http://dx.doi.org/10.1177/095001702400426884 
Siyambalapitiya, S.B. (2005). Higher education in Sri Lanka: a need for a change in attitudes. Sri Lankan Journal of Educational Research, 9(1), 33-43.

Steffy, B.E., Wolfe, M.P., Pasch, H.S., \& Enz, B.J. (2000). The model and its application. In B.E. Steffy, M.P. Wolfe, H.S. Pasch, \& B.J. Enz (Eds.), Life Cycle of the Career Teacher, (pp. 1-25). California: Corwin Press.

Teddlie, C., \& Tashakkori, A. (2009). Foundations of Mixed Methods Research: Integrating Quantitative and Qualitative Approaches in the Social and Behavioural Sciences. California: SAGE Publications, Inc.

Thirunavukkarsu, K. (n.d.). Reintroduction of English as medium of instruction in Sri Lanka: With special reference to Jaffna. International Journal of English Language and Literature Studies, 1(1), 1-8. Retrieved from http://www.aessweb.com/pdf-files/ijells, \%20pp.1-8.pdf

Van Driel, J. H., Verloop, N., de Vos, W. (1998). Developing science teachers' pedagogical content knowledge. Journal of Research in Science Teaching, 35(6), 673-695. http://dx.doi.org/10.1002/(SICI)1098-2736(199808)35:6<673::AID-TEA5>3.3.CO;2-9

Wettewa, V. (n.d.). Education in Globalizing Sri Lanka: The Case of Sri Lankan International Schools. Retrieved from http://www.academia.edu/9107151/EDUCATION_IN_ GLOBALIZING_SRI_LANKA_THE_CASE_OF_SRI_LANKAN_INTERNATIONAL_SCHOOLS 